\title{
ANALISIS NILAI TAMBAH EKONOMI (Economy Value Added) UNTUK MENGUKUR KINERJA KEUANGAN PETANI MINYAK KAYU PUTIH DESA PELA DAN BATU JUNGKU DI WILAYAH KERJA KESATUAN PENGELOLAAN HUTAN PRODUKSI (KPHP) MODEL UNIT III WAE TINA
}

\author{
${ }^{1}$ Willy Marthen Behuku*, ${ }^{2}$ A. Kastanya, ${ }^{3}$ D. V. Pattimahu \\ ${ }^{1,2,3}$ Program Studi Manajemen Hutan, Pascasarjana Universitas Pattimura Ambon \\ Jl. Dr.Ir. M. Latumeten, Kampus PGSD - Ambon 57131 \\ *Penulis Korespondensi Email : willymarthen88@gmail.com
}

Diterima : 11 Juli $2016 \quad$ Disetujui : 15 Agustus 2016

\begin{abstract}
Intisari
Usaha minyak kayu putih yang dikembangkan di wilayah kerja Kesatuan Pengelolaan Hutan Produksi (KPHP) Model Unit III Wae Tina merupakan salah satu mata pencaharian yang telah turun-temurun diusahakan oleh para petani pengrajin kayu putih. Dalam melakukan kajian penelitian analisis nilai tambah ekonomi (economy value added) untuk mengukur kinerja keuangan petani minyak kayu putih di wilayah kerja KPHP Model Unit III Wae Tina, ada dua Desa yang menjadi sampel penelitian, yaitu Desa Pela dan Desa Batu Jungku. Pengolahan minyak kayu putih yang dilakukan oleh para petani pengrajin dikedua Desa tersebut masih dalam skala usaha rumah tangga dengan teknik pengolahan yang sederhana, dan produksi minyak yang dihasilkan juga masih sangat terbatas. Sehingga turut mempengaruhi tingkat kesejahteraan dan kemapanan para petani pengrajin dari segi finansial. Hasil panen daun kayu putih yang kemudian diolah menjadi minyak kayu putih oleh para petani setempat, dari segi finansial menghasilkan benefit yang cukup baik bagi para petani pemilik lahan maupun para karyawan yang bekerja sebagai tenaga pengolah minyak kayu putih. Dari hasil perhitungan nilai tambah ekonomi atau economy value added (EVA) diperoleh nilai yaitu 301.222.845, dimana hasil tersebut menunjukan bahwa nilai tambah ekonomi lebih besar dari nol (EVA $>0$ ). Artinya bahwa perusahaan dalam hal ini masyarakat petani minyak kayu putih yang merupakan bagian dari KPHP Model Unit III Wae Tina dalam operasional usaha minyak kayu putih yang dijalankan terdapat nilai tambah. Dengan kata lain usaha minyak kayu putih yang dilakukan dengan sistem produksi dan distribusi produk dapat dikatakan cukup baik karena mampu menghasilkan nilai tambah bagi para pengusaha yang dapat dijadikan sebagai indikator untuk mengukur keberhasilan dan kelangsungan usaha kedepan.
\end{abstract}

Kata Kunci : Minyak kayu putih, Nilai tambah ekonomi, Petani, Wae Tina

\begin{abstract}
Eucalyptus oil venture which developed in the working area of Production Forest Management Unit (KPHP) Model Unit III Wae Tina, is one of the livelihood for generations have grown by farmers white wood craftsmen. In conducting the research study analyzes the economic value added (economy value added) to measure the financial performance of farmers eucalyptus oil in the working area KPHP Model Unit III Wae Tina, there are two villages in the research samples, the Village and the village of Stone Jungku Pela. Eucalyptus oil processing performed by farmers artisans in both villages are still in the scale of household businesses with simple processing techniques, and the resulting oil production is still very limited. Thus also influence the level of prosperity and stability craftsmen farmers financially. Yields of eucalyptus leaves which are then processed into eucalyptus oil by local farmers, in terms of financial yield considerable benefits for farmers and landowners employees who worked as eucalyptus oil processing. From the calculation of economy value added (EVA) obtained value is 301222 845, where the results showed that the economy added value is greater than zero (EVA>0). This means that companies in this case eucalyptus oil farming communities that are part of the Model Unit III Wae KPHP Tina in business operations run eucalyptus oil are added value. In other words, eucalyptus oil business is conducted with the production and distribution of products can be quite good because it can produce added value for entrepreneurs that can serve as indicators to measure the success and future business continuity.
\end{abstract}

Keyword : District Wae Tina, Economy value added, Eucalyptus oil, Farmer

DOI:10.30598/jhppk.2016.1.1.66

ISSN ONLINE : 2621-8798

Page 66 


\section{PENDAHULUAN}

Luas Tanaman kayu putih (Melaleuca cajuputi sub sp. cajuputi) di Indonesia telah mencapai lebih dari 248.756 hektar (Sunanto, 2003). Tanaman kayu putih banyak terdapat di Jawa dan di Kepulauan Maluku. Di Jawa, Hutan tanaman kayu putih selama ini dikelola oleh Perum Perhutani baik di Jawa Tengah, Jawa Timur maupun Jawa Barat. Sedangkan di Yogyakarta pengelolaan kayu putih dilakukan oleh Dinas Kehutanan dan Perkebunan. Dalam pengelolaan industri kayu putih ini, Perum perhutani maupun Dinas Kehutanan dan Perkebunan Daerah Istimewah Yogyakarta bekerjasama dengan masyarakat disekitar kawasan hutan dengan harapan dapat membuka lapangan kerja dan meningkatkan taraf hidup masyarakat. Peran masyarakat dalam industri kayu putih di Jawa adalah sebagai buruh dalam kegiatan pemanenan daun, pengakutan, proses penyulingan, dan penanganan limbah, maupun sebagai penggarap lahan tumpang sari dengan tanaman palawija disela-sela tanaman kayu putih.

Tanaman kayu putih juga banyak terdapat di Kepulauan Maluku, Pulau Seram, Pulau Buru, dan juga di Nusa Tenggara Timur yang berupa tegakan alam. Di kepulauan Maluku luas tanaman kayu putih diperkirakan mencapai 120.000 ha. Daun dari tanaman kayu putih ini digunakan sebagai bahan baku industri minyak kayu putih, dimana minyak kayu putih dihasilkan melalui proses penyulingan dan kegiatan penyulingan minyak kayu putih pada skala rumah tangga dilakukan dengan menggunakan ketel-ketel tradisional.

Data Badan Pusat Statistik Indonesia pada tahun 2006, dijelaskan bahwa Pulau Buru menjadi penghasil tanaman kayu putih terbesar di kawasan wilayah Negara Kesatuan Republik Indonesia, kemudian di Pulau Seram dan Pulau Ambon. Melihat potensi tanaman kayu putih di indonesia tersebut, maka pengolahan tanaman kayu putih memiliki prospek yang baik untuk dikembangkan.

Salah satu metode baru dalam menilai kinerja keuangan perusahaan yang mencerminkan nilai perusahaan adalah Economic Value Added (EVA) yang di Indonesia dikenal dengan istilah Nilai Tambah Ekonomi (NITAMI). Nilai tambah ekonomi atau EVA pertama kali diperkenalkan oleh Sterwart (dalam A.Sakir, 2009:151) yang mendefenisikan EVA sebagai berikut: "EVA adalah mengukur income residual dikurangi biaya modal dari hasil laba opersai dalam bisnis". EVA akan meningkat seandainya laba operasi dapat tumbuh tanpa meningkatnya biaya modal. Jika laba baru diinvestasikan dalam proyek yang ada atau se-mua proyek yang memperoleh laba lebih daripada biaya modal keseluruhan, dengan kata lain dapat dikatakan bahwa EVA merupakan cara mengukur sisa laba yang dihasilkan perusahaan dengan mengurangi laba opersai dengan biaya modal. Dalam hal ini, EVA akan meningkat jika pertumbuhan atau peningkatan laba operasi tidak diikuti oleh adanya peningkatan modal.

EVA merupakan keuntungan operasional setelah dikurangi pajak dengan biaya modal atau dengan kata lain EVA adalah pengukuran pendapatan sisa (residual income) yang mengurangi biaya modal terhadap laba operasi. Jadi, EVA ditentukan oleh dua hal yaitu keuntungan bersih operasi setelah pajak dan tingkat biaya modal. Laba operasi setelah pajak menggambarkan hasil penciptaan value di perusahaan, sedangkan biaya modal sendiri dapat diartikan sebagai pengorbanan yang dikeluarkan dalam penciptaan value tersebut.

Kesejahteraan para petani pengrajin minyak kayu putih Desa Pela dan Batu Jungku di wilayah kerja Kesatuan Pengelolaan Hutan Produksi (KPHP) Model Unit III Wae Tina belum terukur secara jelas. Hal ini dikarenakan perolehan nilai manfaat secara ekonomi dari usaha minyak kayu putih yang dijalankan belum diketahui pasti oleh para petani pengrajin.

Dari latar belakang permasalahan diatas maka rumusan masalah yang akan dipecahkan adalah bagaimana kinerja keuangan petani pengrajin minyak kayu putih di Desa Pela dan Batu Jungku pada tahun 2015 ditinjau dengan menggunakan analisis nilai tambah ekonomi atau Economic Value Added (EVA). Tujuan dari penelitian ini adalah untuk mengetahui kinerja keuangan petani pengrajin minyak kayu putih di Desa Pela dan Batu Jungku pada tahun 2015 dengan menggunakan analisis nilai tambah ekonomi atau Economic Value Added (EVA). 


\section{METODE PENELITIAN}

\section{Alat dan Objek Penelitian}

Alat yang digunakan dalam penelitian ini adalah alat tulis menulis, kuesioner, alat hitung (kalkulator) didukung dengan software Microsoft office Exel, dan kamera. Objek yang diteliti yaitu dokumen usaha minyak kayu putih dari para pelaku usaha minyak kayu putih yang menjalankan aktivitas usahanya dalam wilayah kerja KPHP Wae Tina (Unit III).

\section{Jenis Dan Sumber Data}

Data yang dikumpulkan dalam penelitian ini adalah data primer dan data sekunder. Data primer diperoleh dari hasil observasi langsung di wilayah kerja KPHP Wae Tina (Unit III) serta pengamatan langsung terhadap kegiatan yang berhubungan dengan penelitian. Data sekunder diperoleh dari instansi pemerintah seperti Dinas Kehutanan Provinsi Maluku dan pihak lain yang terkait untuk mendukung penelitian ini.

\section{Metode Pengumpulan Data}

Pengumpulan data primer dalam penelitian ini dilakukan melalui beberapa cara seperti: 1) Observasi, yaitu teknik pengumpulan data melalui pengamatan langsung terhadap latar dan objek penelitian. 2) Wawancara mendalam (In-depth interview), yaitu dilakukan melalui wawancara mendalam kepada narasumber terpilih atau para stakeholder usaha minyak kayu putih di lokasi penelitian. 3) Focus Group Discusstion (FGD) dengan stakeholders minyak kayu putih di lokasi penelitian.

Pemilihan narasumber dalam studi ini berdasar purposive sampling, di mana pemilihan sampel narasumber dilakukan berdasarkan jenis informasi atau pertimbangan yang sudah ada/ditetapkan sebelumnya dan adanya identifikasi atas kelompok/ orang yang memiliki kekhususan tertentu (terkait jabatan, kepakaran/ expert sampling, dan pengalaman dalam usaha minyak kayu putih). Namun di lapangan, sebagai bagian dari metode purposive sampling adalah dimungkinkan dan bahkan didorong untuk pengembangan kategori/subjek narasumber lain berdasarkan teknik snowballing (berdasarkan keterkaitan informasi, rekomendasi nama, dst).

Bertolak dari teknik tersebut, narasumber yang diwawancarai merupakan stakeholders pengrajin kayu putih yang terkait langsung dengan rantai nilai dan rencana bisnis minyak kayu putih di wilayah kerja dari KPHP Wae Tina (Unit III) yakni petani, pengepul tingkat desa/kecamatan, pengepul besar, penyedia sarana produksi, penyuluh serta Pejabat Kesatuan Pengelolaan Hutan Produksi (KPHP) Model Unit III Wae Tina dan para pejabat SKPD terkait.

\section{Metode Analisis Data}

Metode analisis data yang digunakan adalah analisis nilai tambah ekonomi atau Economy Value Added (EVA). menurut Tunggal dalam dan kemudian secara sederhana dirumuskan oleh Tunggal (2000) dengan tahapan analisis sebagai Pada tabel 1.

Tabel 1. Metode Analisis Data

\begin{tabular}{ll}
\hline Analisis & Rumus \\
\hline $\begin{array}{l}\text { Menghitung NOPAT } \\
\text { (Net Operating After } \\
\text { Tax) }\end{array}$ & $\begin{array}{l}\text { NOPAT = Laba (Rugi) Usaha - Pajak } \\
\text { operatin yang merupakan laba sebelum bunga. Pajak yang digunakan } \\
\text { dalam perhitu EVA adalah pengorbanan yang dikeluarkan oleh } \\
\text { perusahaan dalam pencip nilai tersebut. }\end{array}$ \\
\hline 2. Invested Capital & $\begin{array}{l}\text { Invested Capital = Total Hutang \& Ekuitas - Hutang Jk. Pendek } \\
\text { Ket: Total hutang dan ekuitas menunjukkan beberapa bagian dari setiap rupiah mo } \\
\text { sendiri yang dijadikan jaminan utang. Pinjaman jangka pandek tanpa bunga merup } \\
\text { pinjaman yang digunakan perusahaan yang pelunasan maupun pembayarannya ak } \\
\text { dilakukan dalam jangka pendek (satu tahun sejak tanggal neraca) dengan menggun } \\
\text { aktiva lancar yang dimiliki perusahaan, dan atas pinjaman itu tidak dikenai bunga, } \\
\text { seperti hutang usaha, hutang pajak, biaya yang masih harus dibayar, dan lain-lain. }\end{array}$
\end{tabular}




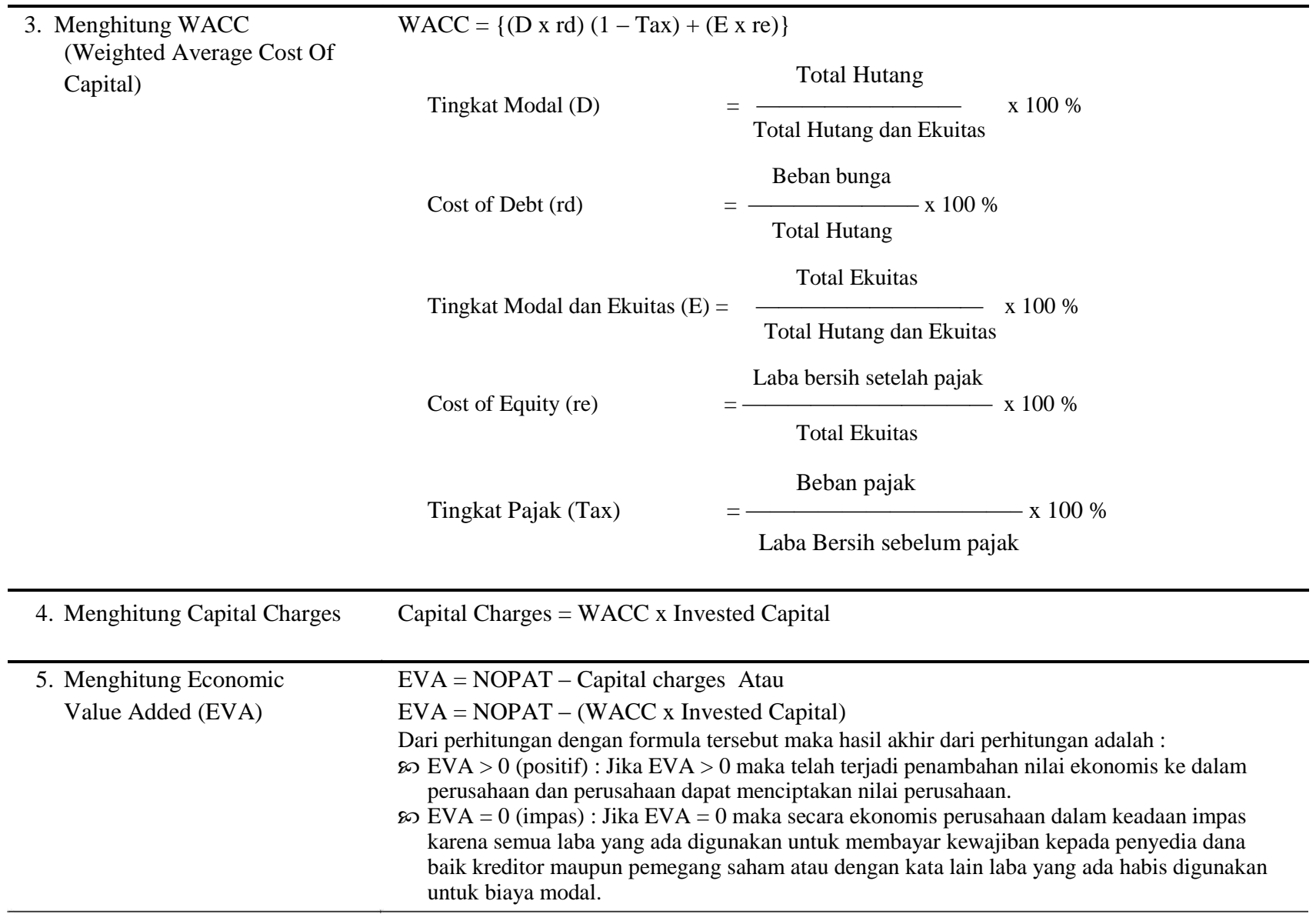

\section{HASIL DAN PEMBAHASAN}

Perhitungan nilai tambah ekonomi atau economy value added (EVA) pada usaha minyak kayu putih yang dijalankan oleh petani Desa Pela dan Batu Jungku di wilayah kerja KPHP Model Unit III Wae Tina dilakukan dengan menganalisis komponen biaya yang diperoleh dari hasil survei langsung dilapangan pada petani pengrajin minyak kayu putih, dimana standar biaya yang digunakan adalah berdasarkan Standar Akuntansi
Pemerintahan (PP Nomor 71 Tahun 2010 \& Permendagri Nomor 64 Tahun 2013). Adapun nilai dari setiap komponen biaya yang dipakai dalam analisis adalah sebagai berikut : Hasil per-hitungan analisis nilai tambah ekonomi atau economy value added (EVA) adalah sebagai berikut :

\section{NOPAT ( Net Operating After Tax) Rumus NOPAT \\ $=$ Laba (Rugi) Usaha - Pajak}

Tabel 1. Komponen Biaya

\begin{tabular}{lc}
\hline \multicolumn{1}{c}{ KOMPONEN BIAYA } & JUMLAH (Rp) \\
\hline Total laba (rugi) usaha & 2.322 .000 .000 \\
Total Pajak (10\%) & 232.200 .000 \\
Total Beban/Biaya & 869.330 .000 \\
Total Beban Bunga & 127.356 .845 \\
Total Kewajiban & 1.228 .886 .845 \\
Total Aset & 2.322 .000 .000 \\
Total Ekuitas & 1.093 .113 .155 \\
\hline
\end{tabular}

Sumber : Hasil Analisis Data Tahun 2015 
$=2.322 .000 .000-232.200 .000$

$=2.089 .800 .000$

2. Invested Capital

Rumus Invested Capital

$=$ Total Hutang \& Ekuitas - Hutang Jk. Pendek

$=1.962 .443 .155-173.866 .000$

$=1.788 .577 .155$

3. WACC (Weighted Average Cost Of

Capital) Rumus WACC

$=\{(\mathrm{D} \times \mathrm{rd})(1-\mathrm{Tax})+(\mathrm{E} \times \mathrm{re})\}$

Dimana :
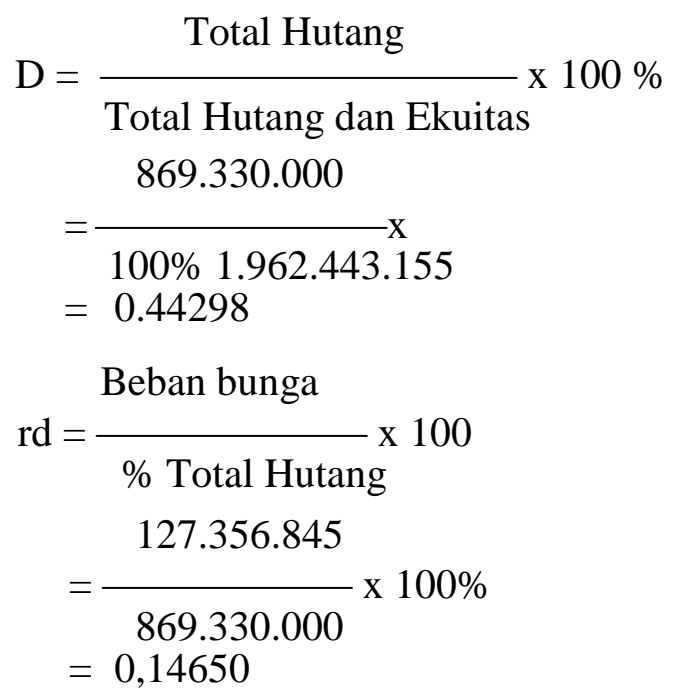

Total Ekuitas

$\mathrm{E}=\frac{}{\text { Total Hutang dan Ekuitas }} \times 100 \%$

1.093.113.155

$=\frac{1.093 .113 .155}{1.962 .443 .155} \times 100 \%$

$=0,55702$

Laba bersih setelah pajak

$$
\begin{aligned}
\text { re } & =\frac{\% \text { Total Ekuitas }}{1.220 .470 .000} \times 100 \\
& =\frac{1.093 .113 .155}{1} \times 100 \% \\
& =1,11651
\end{aligned}
$$

Beban pajak

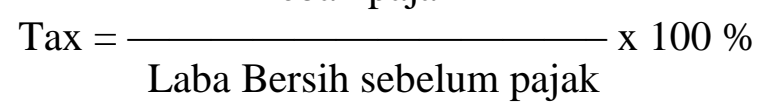

$$
\begin{aligned}
& =\frac{}{1,325,313,155} \times 100 \% \\
& =0.17520
\end{aligned}
$$

$$
\begin{aligned}
\text { WACC }= & \{(0.44298 \times 0,14650)(1-0.17520) \\
& +(0,55702 \times 1,11651)\} \\
= & 0,67544
\end{aligned}
$$

\section{Menghitung Capital Charges}

Rumus Capital Charges

$=$ WACC $\mathrm{x}$ Invested Capital

$=0,67544 \times 1.788 .577 .155$

$=1.788 .577 .155$

\section{Economic Value Added (EVA)}

Rumus EVA

$=$ NOPAT - Capital charges

$=2.089 .800 .000-1.788 .577 .155$

$=301.222 .845$

Dari hasil perhitungan EVA diatas diperoleh nilai yaitu 301.222.845, dimana hasil tersebut menunjukan bahwa EVA lebih besar dari nol (EVA > 0). Artinya bahwa perusahaan dalam hal ini masyarakat petani minyak kayu putih yang merupakan bagian dari KPHP Unit III Wae Tina dalam operasional usaha minyak kayu putih terdapat nilai tambah. Dengan kata lain usaha minyak kayu putih yang dilakukan dengan sistem produksi dan distribusi produk yang dapat dikatakan cukup baik karena mampu menghasilkan nilai tambah bagi para pengusaha yang dapat dijadikan sebagai indikator untuk mengukur keberhasilan dan kelangsungan usaha kedepan.

\section{KESIMPULAN}

Dari hasil analisis nilai tambah ekonomis atau economy added value (EVA) diperoleh hasil yang positif yaitu Rp. 301.222.845, dengan artian bahwa dengan teknik pegnolahan lokal (local processing techniques) dalam mengolah daun kayu putih menjadi produk minyak, mampu memberi kontribusi nilai tambah yang nyata. Maka peluang para petani minyak kayu putih di Desa Pela dan Batu Jungku pada wilayah kerja KPHP Model Unit III Wae Tina untuk mengelolah bisnisnya dengan teknik yang lebih modern pasti akan lebih menguntungkan. 


\section{DAFTAR PUSTAKA}

Gulo, W. A., dan Ermawati. W. J. Analisis Economy Value Added (EVA) dan Market Value Added (MVA) Sebagai Alat Pengukur Kinerja Keuangan P T S A . Jurnal Manajemen dan Organisasi Vol II, No. 2, Agustus 2011. Departemen Manajemen Fakultas Ekonomi dan Manajemen Institut Pertanian Bogor.

Prabowo, H., 2004. Journal The WINNERS, Vol. 5 No. 1, Maret 2004: 19-33. Penerapan Economic Value Added Untuk Memaksimalkan Nilai Perusahaan: Studi Kasus PT XYZ. Staf Pengajar Jurusan Manajemen, Fakultas Ekonomi, UBiNus, Jakarta.

Simbolon, Ratih F D,. Dzulkirom, Moch., Saifi, Muhammad. Analisis Eva (Economic Value Added) Untuk Menilai Kinerja Keuangan Perusahaan (Studi Pada Perusahaan Farmasi Pada Bursa Efek Indonesia Periode 2010-2012). Fakultas Ilmu Administrasi Universitas Brawijaya,. Malang, 2012

Tunggal : 2001, Dalam Anonim, 2015. Langkah langkah untuk menghitung EVA yang lebih sederhana.pasti akan lebih menguntungkan. 